ORGINAL ARTICLE

\title{
ANATOMICAL BARRIERS IN CONGENITAL CANAL ATRESIA AFFECTING OPERATIVE CANDIDACY AND PATIENT SELECTION
}

\author{
Wael A. Alzamil, MD, Otorhinolaryngology, Hearing and Speech Institute, Cairo, Egypt.
}

Corresponding Author:

Wael A. Alzamil

dr_waelzamil25@yahoo.com

Assistant Professor

$\begin{array}{ll}\text { Submit } & 2021-08-23 \\ \text { Date } & 02: 31: 55 \\ \text { Revise } & 2021-08-30 \\ \text { Date } & 19: 54: 04 \\ \text { Accept } & 2021-09-23 \\ \text { Date } & 23: 17: 45\end{array}$

Background: By analyzing the temporal CT images and intraoperative findings in patients with canal atresia and comparing those with images and intraoperative findings of normal canals, we further understand external and middle ear development to improve surgical candidacy selection. In addition to the status of the ossicular chain, the degree of development of the tympanic cavity and mastoid, and the course of the facial nerve, the most important information taken from CT and intraoperative findings are the dimensions of the future canal. This study will focus on the dimensions of the created canal and whether it is correctable or uncorrectable.

Aim of the study: To match the C.T. scan and intraoperative findings with the surgical outcome for patients with congenital canal atresia for proper surgical candidacy considerations.

Patients and methods: A prospective, study conducted from September 2017 to December 2020 on 50 congenital canal atresia patients. All patients have undergone surgical meatocanaloplasty. Intraoperative data collection was done to be matched with preoperative C.T. data and correlated later on with the final outcome.

Results: Follow up of all patients recorded progressive circumferential narrowing of their canals and progressive reduction of their depth. Final outcome showed narrow short canals in all patients.

Conclusion: Analysis of the C.T. data and intraoperative findings in patients of congenital canal atresia showed uncorrectable dimensions even for those patients with the highest Jahrsdoerfer score due to lack of full dimension consideration.

Key words: Congenital anatomical Barriers, None corrected dimensions, Congenital Canal Atresia.

\section{INTRODUCTION}

$\mathbf{B}^{y}$ $y$ the thirteenth week, a disk-like plug comes into contact with the primordial malleus medially, contributing to the future tympanic membrane. By the fifteenth week, it splits, leaving behind a thin ectodermal cell layer of the immature tympanic membrane. A continuation of the thin skin of the pinna lines the entire external auditory canal and the outer surface of the tympanic membrane. The external auditory canal is completely patent and expands to its complete form by the eighteenth week (1).
The temporal bone consists of four parts,

the squamous, mastoid, petrous and tympanic parts. The squamous part is the largest and most superiorly positioned relative to the rest of the bone. The zygomatic process is a long, arched process projecting from the lower region of the squamous part andt articulates with the zygomatic bone. Postero inferior to the squamous is the mastoid part. Fused with the squamous and mastoid parts and between the sphenoid and occipital bones lies the petrous part (2). The tympanic part is relatively small and lies inferior to the 
squamous part, anterior to the mastoid part, and superior to the styloid process (3).

The external auditory canal is derived from the first branchial cleft after resorption of the ectodermal thickening leaving a thin layer of ectoderm (skin or stratified squamous epithelium) lining the canal and tympanic membrane (4). The cartilaginous and bony portions of the canal are derived from the mesoderm of the first and second branchial arches. The outer cartilaginous one third is continuous with the pinna cartilages. The inner bony two thirds are composed of the tympanic ring, squamous portion and mastoid portion superiorly and posteriorly respectively (5).

Surgery for congenital aural atresia usually has unfavorable prognosis. So authors have developed a grading schemes based on the preoperative temporal bone CT scan and the appearance of the external ear. Jahrsdoerfer scoring system was the most popular one in which patients were graded on a possible best score of 10 (6). The stapes is assigned the highest rating ( 2 points), while all other entrees on the scale are 1 point Table 1. The grade assigned preoperatively has been supposed to correlate well with the patient's chance of success regarding postoperative speech reception threshold. The grading system aims to avoid non indicated surgeries allowing proper prediction of the hearing outcome. Whoever in our practice different scenarios exist. Prediction of the outcome was not always possible by this grading system. This may be due to other factors or parameters which are not involved in the grading system or may be as a result of uncorrectable factors which means inoperability (7).

So proper understanding of the embryology and the development of the external auditory canal should alter the concept of meatal atresia from just failure of canalization to agenesis of the canal. The external auditory canal is not a negative structure, whoever it can be considered an organ with its own constituents and dimensions. So, in canal atresia the bony and cartilaginous walls are partially or completely absent. Their developmental absence will need creating the canal rather than reconstructing it. Creation of the auditory canal means that we should imitate its normal dimensions including its depth and its diameter. Regarding the normal auditory canal length or depth it measures about 2.5 centimeters ( 1 inch) in length (from the tragus to the tympanic membrane) and 0.7 centimeters (0.3 inch) in diameter and is curved in an $\mathrm{S}$ shape direction. In patients with canal atresia we find the distance between the tragus and the outer wall of the middle ear to be shorter than normal due to underdevelopment of bony and cartilaginous constituents (figure 1). Beside this shallow distance the depth of the surrounding tissues is reduced as a result of the hypoplasia affecting the first and second branchial arches derivatives. All these facts regarding morbid anatomy will definitely limit any surgeon to correct the depth or the length of the canal because the middle ear is near to the surface (9).

The normal external canal has nearly a cylindrical skeleton or framework formed of bone and cartilage. For proper correction of canal atresia we try to obtain the cylindrical skeleton to keep the canal patent which never to happen during surgery (10). Only we get a shallow superior and posterior bony boundaries due to hypoplastic mastoid and squamous bones beside very short anterior and inferior bony boundaries due to rudimentary tympanic ring and tempromandibular joint. In addition, there is absent cartilaginous portion of the canal due to rudimentary cartilaginous vestiges which cannot form a solid cylinder. So, beside the shallow cavity or proposed canal there is defects in the solid boundaries of the canal to be replaced by the surrounding soft tissues (figure 2). These defects will definitely lead to later collapse and contraction of the created cavity or canal beside the gradual process of fibrosis and healing by secondary intention leading to more narrow and shallow cavity (11).

As regards the caliber of the canal, it has a diameter range from 0.7 to $1 \mathrm{~cm}$ in its 
antero-posterior and supero-inferior dimensions. Before atresia surgery we usually look for the thickness of the atretic plate and the distance between the sigmoid sinus and the temperomandibular joint to measure the antero-posterior dimension (12). In rare mild cases with incomplete agenesis the atretic plate has a fair antero-posterior dimension (not less than $1 \mathrm{~cm}$ ) we can perform the anterior approach by removing the atretic plate. Whoever, in the majority of patients there is narrow plate forcing us to perform the posterior approach in which we do radical mastoidectomy to maximize the anteroposterior distance between the sigmoid sinus and the temperomandibular joint (13).

Regarding the other diagonal which is the supero-inferior dimension, it is usually overlooked or omitted during the preoperative evaluation. This dimension is very important and critical. The superior bony canal wall in the inner two thirds is formed by squamous portion of the temporal bone and its zygomatic process forming what is called the outer attic mass or the lateral boundary of the attic region. The inferior wall is formed of the floor of the tympanic ring. In cases of complete canal atresia, the superior wall is less affected whoever the inferior wall is short in its width and acquires a higher level due to underdeveloped tympanic ring leading to marked decrease in the vertical or superoinferior dimension. Intraoperative drilling of the outer attic mass removing it (Atticotomy) may increase this dimension but to a limit which may be insufficient (figure 4). So drilling is limited superiorly by the dura and inferiorly by the soft tissue, parotid or anomalous facial nerve course with the rudimentary tympanic ring. As regards the cartilaginous outer one third, in cases of complete atresia with anotia or grade III microtia there will be rudimentary malformed cartilage vestiges which cannot be utilized to reconstruct the canal. In my study, I have revised in details the C.T. data and comparing it with the intraoperative findings and the postoperative coarse regarding the healing process and hearing improvement.

Patients and methods:
A prospective, study conducted from September 2017 to December 2020 on 50 patients suffering congenital canal atresia. Bilateral cases and unilateral above the age of 8 were included in the study. 36 patients have bilateral atresia and 14 patients with unilateral atresia. Age distribution has a range of 4-18.5 years old with a main of 8.3 years. Sex distribution showed slight male predominance by 28 male patients $56 \%$ versus 22 female patients $44 \% .47$ patients have presented clinically with complete atresia and three patients with partial atresia having shallow and narrow canals. Patients have been subjected to detailed history taking and thorough general and local examination to identify possible perinatal risk factors or relevant family history and to exclude other congenital anomalies which may interfere with surgery. All patients in the study were subjected to preoperative audiological assessment and high resolution C.T. scanning. Regarding the audiological assessment was done by pure tone audiometry (PTA), free field audiometry (FFA) and auditory brain stem response (ABR) according to patient's age and IQ. All patients in the study have a Jahrsdoerfer scores above 6 as an inclusion criteria. All patients have undergone surgical meatocanaloplasty via anterior approach or posterior approach according to the C.T. findings. Intraoperative data collection was done to be matched with preoperative C.T. data and correlated later on with the final outcome. Postoperative regular follow up visits were done regularly every two to three weeks for regular packing. Packing by merocel was an essential step for at least six months to avoid restenosis by tissue memory.

Excluded from the study, recurrent cases, acquired or traumatic atresia or stenosis and patients with unserviceable hearing as detected by ABR or PTA. Also unilateral atresia with age less than 8 years was excluded from the study.

The minimal follow up period was six months but patients in the start of the study have been followed for 3-4 years. I have found that changes in dimensions were nearly constant after six months. 
There are three categories of measurements for each patient in the study. These measurements are the preoperative C.T. scan dimensions; (table 2), the intraoperative dimensions; (table 3) and the postoperative clinical dimensions (table 4).

The preoperative C.T. scan dimensions are five starting by the antero posterior distance between TMJ and sigmoid sinus in axial cuts with a range of 3.8 to $4.6 \mathrm{~cm}$, mean of $4.1 \mathrm{~cm} \pm .3 \mathrm{SD}$, the supero inferior distance between the Dura and tympanic bone in coronal cuts with a range of 2.1 to $3.4 \mathrm{~cm}$, mean of $2.6 \mathrm{~cm} \pm .2 \mathrm{SD}$, the depth of the middle ear in axial and coronal cuts with range of 1.2 to $2.5 \mathrm{~cm}$, mean of $1.8 \mathrm{~cm} \pm .3$ $\mathrm{SD}$, the thickness of the inferior tympanic bone in coronal cuts with a range of .3 to. 6 $\mathrm{cm}$, mean of. $4 \mathrm{~cm} \pm .1 \mathrm{SD}$ and finally the length of the anterior bony wall in axial cuts with a range of .8 to $1.2 \mathrm{~cm}$, mean of $1 \mathrm{~cm} \pm$ $.1 \mathrm{SD}$.

The intraoperative dimensions; (table 3) were also five starting by the antero posterior distance between anterior bony wall and sinus plate with range of 3.5 to $4.3 \mathrm{~cm}$, mean of 4 $\mathrm{cm} \pm .2 \mathrm{SD}$, the supero inferior distance between the Dural plate and tympanic floor with a range of 1.9 to $3.1 \mathrm{~cm}$, mean of $2.5 \mathrm{~cm}$ $\pm .2 \mathrm{SD}$, the depth of the middle ear with a range of 1.2 to $2.4 \mathrm{~cm}$, mean of $1.7 \pm .3 \mathrm{SD}$, the length of the inferior bony wall with a range of .4 to. $8 \mathrm{~cm}$, mean of $.6 \mathrm{~cm} \pm .2 \mathrm{SD}$ and finally the length of the anterior bony wall with a range of 1 to $1.2 \mathrm{~cm}$, mean of 1.1 $\mathrm{cm} \pm .1 \mathrm{SD}$.

Regarding the postoperative clinical dimensions; (table 4) will be detailed in the results section. Measurements will involve the canal depth, maximal mid-canal width and meatal diameter after 1 month, 3 months and 6 months.

Ethics:

The ethics committee of our institution approved this work according to the Declaration of Helsinki. A detailed informed consent was obtained from each patient.

Operative Procedure:

After periosteal elevation we start to localize certain anatomical landmarks to adjust our drilling in the proper location. The most important and nearly constant landmarks are the temperomandibular joint (the anterior limit) and the zygomatic root which marks the dural level (the superior limit). In patients with narrow atretic plate with marked underdevelopment or very short the tympanic ring (figure 2) and mastoid bone we performed the posterior approach by doing modified radical mastoidectomy to maximize the antero-posterior dimension. The narrow atretic plate describes the obstructing bony plate opposite the mesotympanum taking its vertical and horizontal dimensions, so its narrowness parallels the marked reduction in the middle ear dimensions. We started at the anterosuperior angle between the line of the temperomandibular joint and the line of dural plate which is marked by the zygomatic process of the squamous bone and the zygomatic bone. Drilling up to dural plate superiorly and the TMJ anteriorly by doing Atticotomy to get access to the epitympanum then we continue drilling posteriorly to exenterate mastoid air cells to reach the sigmoid sinus and sinodural angle. We lower the facial ridge taking care of possible anomalous facial nerve course. After that we continue drilling inferiorly in the rudimentary tympanic ring. We found that inferior drilling is markedly limited by several factors. The first factor was the markedly hypoplastic tympanic ring in its width and height and the small sized mesotympanum and hypotympanum. The second factor is the anomalous facial nerve which may acquire more anterior position. In patients with wide atretic plate and less hypoplastic tympanic ring and mastoid process, we performed the anterior approach by removing the atretic plate only without mastoidectomy. Also with this approach we start drilling at the anterosuperior angle as the safest point by performing Atticotomy removing the outer attic mass then we proceed posteriorly and inferiorly to reach a suitable canal diameter. Then we apply a temporalis fascial graft_over the ossicular chain which is usually hypermobile and splinting the graft by Gelfoam in the middle ear cavity and over the 
graft. The hyper mobility of the ossicular chain was mainly due to lack of ligamentous support after removal of the outer attic mass and drilling the incus buttress which carries the fossa incudes supporting the incus short process by its ligament. The next step was meatoplasty. To obtain a wide meatus we excise soft tissue and cartilaginous remnants opposite the created canal to reach double or triple its normal diameter $(1.5-2.5 \mathrm{~cm})$ and to compensate the suspected postoperative stenosis. We centralize the created meatus opposite the created canal by anchoring sutures to the periostium in three different directions and antibiotic soaked gauze packing. .

Regular Merocel packing was an essential and pivotal step due to its stored static power of expansion which lead to gradual dilatation and canal widening.

Statistical analysis:

50 patients with congenital canal atresia included in the study. 36 patients have bilateral atresia and 14 patients with unilateral atresia. Age distribution has a range of 4-18.5 years old with a main of 8.3 years. Sex distribution showed slight male predominance by 28 male patients $56 \%$ versus 22 female patients $44 \% .47$ patients have presented clinically with complete atresia and three patients with partial atresia having shallow and narrow canals. Regarding my program I have used the Fisher exact test instead of Chisquare test due to the relatively small sized sample. We assess the null hypothesis of independence $\mathrm{P}>0.05$ is the probability that the null hypothesis is true. A statistically significant test result $(\mathrm{P} \leq 0.05)$ means that the test hypothesis is false or should be rejected. A P value greater than 0.05 means that no effect was observed.

The significance and insignificance values compare the preoperative C.T. scan measurements and intra operative dimensions on one side and the follow up clinical measurements on the other side. As we measured the preoperative dimensions and calculating its maximal diagonals in all directions expecting the persistence of its wideness or insignificant decrease. So we explore our results whether there is significant or insignificant changes.

\section{RESULTS}

Data collection was done involving C.T. scan measurements, intraoperative anatomical dimensions, complications, immediate and late postoperative results including the final outcome.

Postoperative clinical dimensions Table 4, involve the canal depth, mid-canal width and meatal diameter. These measurements were recorded after one month, three months and six months postoperatively. All patients recorded progressive circumferential narrowing of their canals and progressive reduction their depth. The canal depth after one month has a range of 1.1 to $2.1 \mathrm{~cm}$, mean of $1.5 \mathrm{~cm} \pm .4 \mathrm{SD}$. the depth after three months recorded range of .9 to $1.7 \mathrm{~cm}$, mean of $1.3 \mathrm{~cm} \pm .3 \mathrm{SD}$. After six months the range of depth was .7 to $1.5 \mathrm{~cm}$, mean of $1.1 \mathrm{~cm} \pm$ $.2 \mathrm{SD}$.

The maximal mid-canal width was calculated indirectly by measuring the maximal cross sectional diameter of the removed merocel pack which take the shape of the cavity during its 2-3 weeks stay and fail to increase in size after removal due its firm texture. After one month, it has a range of 3,5 to $4.2 \mathrm{~cm}$, mean of $2.9 \mathrm{~cm} \pm .2 \mathrm{SD}$. the depth after three months recorded range of 2.9 to $3.8 \mathrm{~cm}$, mean of $3.4 \mathrm{~cm} \pm .2 \mathrm{SD}$. After six months the range of depth was 1.6 to $3.2 \mathrm{~cm}$, mean of $2.1 \mathrm{~cm} \pm .2 \mathrm{SD}$.

The meatal diameter after one month has a range of 2,3 to $2.8 \mathrm{~cm}$, mean of $2.5 \mathrm{~cm}$ $\pm .2 \mathrm{SD}$. the depth after three months recorded range of 1.9 to $2.6 \mathrm{~cm}$, mean of $2 \mathrm{~cm} \pm .2 \mathrm{SD}$. After six months the range of depth was .8 to $1.6 \mathrm{~cm}$, mean of $1.2 \mathrm{~cm} \pm .2 \mathrm{SD}$.

So there was significant progressive reduction in all dimensions through out the follow up period with $\mathrm{P}$ value $\leq 0.05$.

No major intraoperative complications were recorded except one 4 years old female who suffered ipsilateral immediate postoperative complete facial paralysis due to thermal injury caused by the drill. The facial nerve has regained its complete recovery after 4

months. 


\section{Table 1. Jahrsdoerfer Grading Scale Score}

\section{for Congenital Aural Atresia}

Anatomical Structure

Stapes bone

Oval window open

Middle ear space

Facial nerve

Malleus-incus complex

Mastoid pneumatization

Incus-stapes connection

Round window

External ear

Total Possible Score

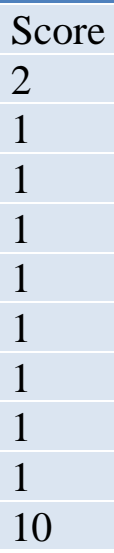

\section{Table 2. Preoperative C.T. scan dimensions;}

\begin{tabular}{|c|c|c|c|}
\hline & Dimensions & Range & Mean \\
\hline $1-$ & $\begin{array}{l}\text { Antero posterior distance between } \\
\text { TMJ and sigmoid sinus in axial cuts. }\end{array}$ & $\begin{array}{l}3.8 \text { to } \\
4.6 \mathrm{~cm}\end{array}$ & $\begin{array}{l}4.1 \mathrm{~cm} \\
\pm .3 \mathrm{SD}\end{array}$ \\
\hline 2 & $\begin{array}{l}\text { Supero inferior distance between the } \\
\text { Dura and tympanic bone in coronal } \\
\text { cuts }\end{array}$ & $\begin{array}{l}2.1 \text { to } \\
3.4 \mathrm{~cm}\end{array}$ & $\begin{array}{l}2.6 \mathrm{~cm} \\
\pm .2 \mathrm{SD}\end{array}$ \\
\hline $3-$ & $\begin{array}{l}\text { Depth of the middle ear in axial and } \\
\text { coronal cuts }\end{array}$ & $\begin{array}{l}1.2 \text { to } \\
2.5 \mathrm{~cm}\end{array}$ & $\begin{array}{l}1.8 \mathrm{~cm} \\
\pm .3 \mathrm{SD}\end{array}$ \\
\hline & $\begin{array}{l}\text { Thickness of the inferior tympanic } \\
\text { bone in coronal cuts }\end{array}$ & $\begin{array}{l}.3 \text { to. } 6 \\
\mathrm{~cm}\end{array}$ & $\begin{array}{l}.4 \mathrm{~cm} \pm \\
.1 \mathrm{SD}\end{array}$ \\
\hline & $\begin{array}{l}\text { Length of the anterior bony wall in } \\
\text { axial cuts }\end{array}$ & $\begin{array}{l}.8 \text { to } 1.2 \\
\mathrm{~cm}\end{array}$ & $\begin{array}{l}1 \mathrm{~cm} \pm \\
.1 \mathrm{SD}\end{array}$ \\
\hline
\end{tabular}

\section{Table 3. Intraoperative dimensions}

\begin{tabular}{|c|c|c|c|}
\hline & Dimensions & Range & mean \\
\hline $1-$ & $\begin{array}{l}\text { Antero posterior } \\
\text { distance } \\
\text { anterior between } \\
\text { and sinus plate }\end{array}$ & 3.5 to $4.3 \mathrm{~cm}$ & $4 \mathrm{~cm} \pm .2 \mathrm{SD}$ \\
\hline $2-$ & $\begin{array}{l}\text { Supero inferior } \\
\text { distance between the } \\
\text { Dural plate and } \\
\text { tympanic floor }\end{array}$ & 1.9 to $3.1 \mathrm{~cm}$ & $2.5 \mathrm{~cm} \pm .2 \mathrm{SD}$ \\
\hline $3-$ & $\begin{array}{l}\text { Depth of the middle } \\
\text { ear }\end{array}$ & 1.2 to $2.4 \mathrm{~cm}$ & $1.7 \pm .3 \mathrm{SD}$ \\
\hline 4- & $\begin{array}{l}\text { Length of the inferior } \\
\text { bony wall }\end{array}$ & .4 to. $8 \mathrm{~cm}$ & $.6 \mathrm{~cm} \pm .2 \mathrm{SD}$ \\
\hline $5-$ & $\begin{array}{l}\text { Length of the anterior } \\
\text { bony wall }\end{array}$ & 1 to $1.2 \mathrm{~cm}$ & $1.1 \mathrm{~cm} \pm .1 \mathrm{SD}$ \\
\hline
\end{tabular}




\section{Table 4. Postoperative clinical measurements}

\begin{tabular}{|c|c|c|c|c|c|c|}
\hline \multirow[t]{2}{*}{ Dimension } & \multicolumn{2}{|c|}{ After one month } & \multicolumn{2}{|c|}{ After 3 months } & \multicolumn{2}{|c|}{ After 6 months } \\
\hline & Range & Mean & Range & Mean & Range & Mean \\
\hline Canal depth & $\begin{array}{l}1.1 \text { to } \\
2.1 \mathrm{~cm}\end{array}$ & $\begin{array}{l}1.5 \mathrm{~cm} \pm \\
.4 \mathrm{SD}\end{array}$ & $\begin{array}{l}.9 \text { to } 1.7 \\
\mathrm{~cm}\end{array}$ & $\begin{array}{l}1.3 \mathrm{~cm} \pm \\
.3 \mathrm{SD}\end{array}$ & $\begin{array}{l}.7 \text { to } 1.5 \\
\mathrm{~cm}\end{array}$ & $1.1 \mathrm{~cm} \pm .2 \mathrm{SD}$ \\
\hline $\begin{array}{l}\text { Maximal mid-canal } \\
\text { width }\end{array}$ & $\begin{array}{l}3.5 \text { to } \\
4.2 \mathrm{~cm}\end{array}$ & $\begin{array}{l}2.9 \mathrm{~cm} \pm \\
.2 \mathrm{SD}\end{array}$ & $\begin{array}{l}2.9 \text { to } \\
3.8 \mathrm{~cm}\end{array}$ & $\begin{array}{l}3.4 \mathrm{~cm} \pm \\
.2 \mathrm{SD}\end{array}$ & $\begin{array}{l}1.6 \text { to } \\
3.2 \mathrm{~cm}\end{array}$ & $2.1 \mathrm{~cm} \pm .2 \mathrm{SD}$ \\
\hline Meatal diameter & $\begin{array}{l}2.3 \text { to } \\
2.8 \mathrm{~cm}\end{array}$ & $\begin{array}{l}2.5 \mathrm{~cm} \pm \\
.2 \mathrm{SD}\end{array}$ & $\begin{array}{l}1.9 \text { to } \\
2.6 \mathrm{~cm}\end{array}$ & $\begin{array}{l}2 \mathrm{~cm} \pm \\
.2 \mathrm{SD}\end{array}$ & $\begin{array}{l}.8 \text { to } 1.6 \\
\mathrm{~cm}\end{array}$ & $1.2 \mathrm{~cm} \pm .2 \mathrm{SD}$ \\
\hline
\end{tabular}

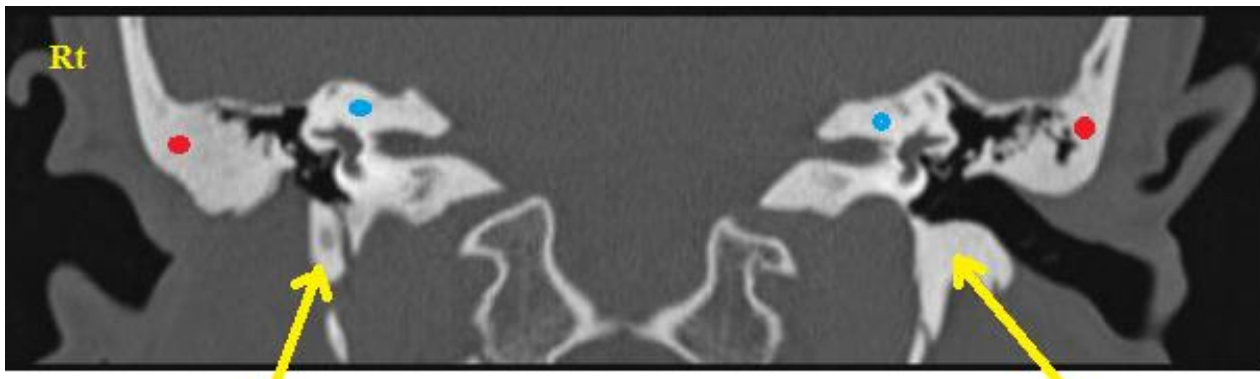

Figure 1; C.T. scan coronal cut in patient with unilateral right canal atresia showing rudementary right tympanic ring and mastoid in contrast to the normal well formed left tympanic and mastoid bones. bilateral well formed squamous and petrous bones in the affected and normal sides. red and blue dots

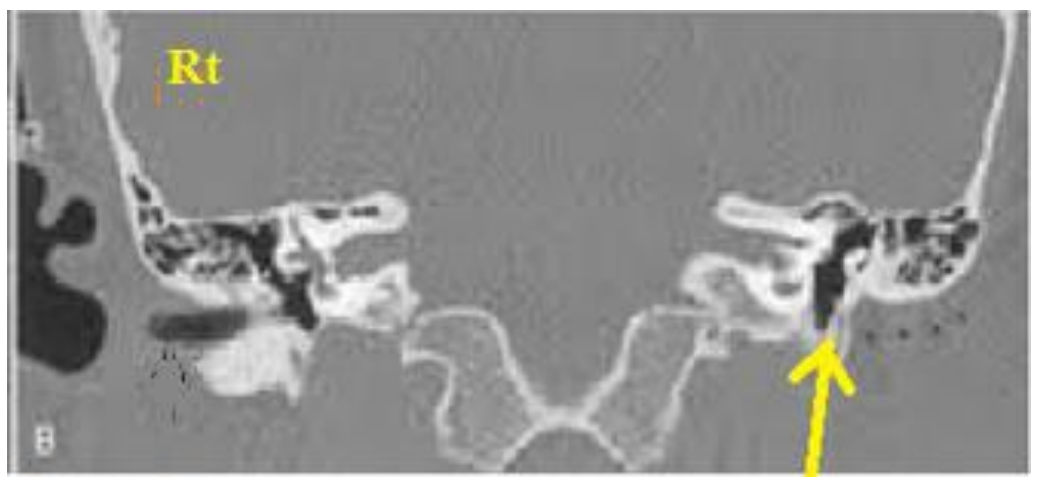

Figure 2;

Coronal C.T. cuts showing marked hypoplastic tympanic bone relative to the well formed right tympanic bone forming the floor of the canal. 


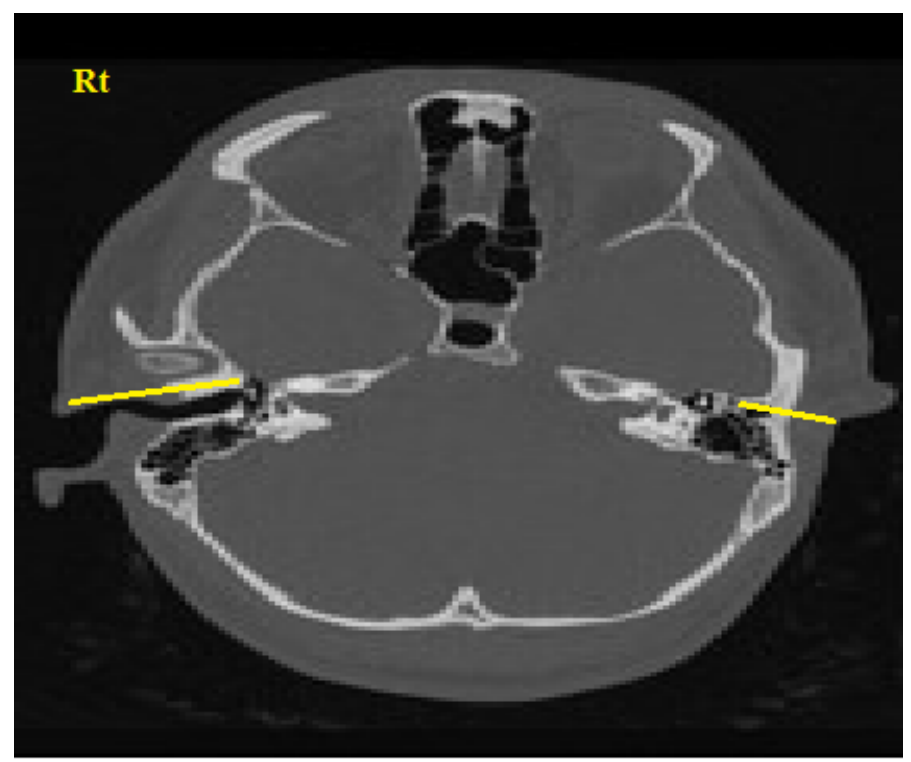

Figure 3: Axial C.T. cut showing the marked differrence in depth between right normal side and the left atretic side marked by the yellow lines. this reflects the shallow left side as a whole leading to uncorrectable depth.

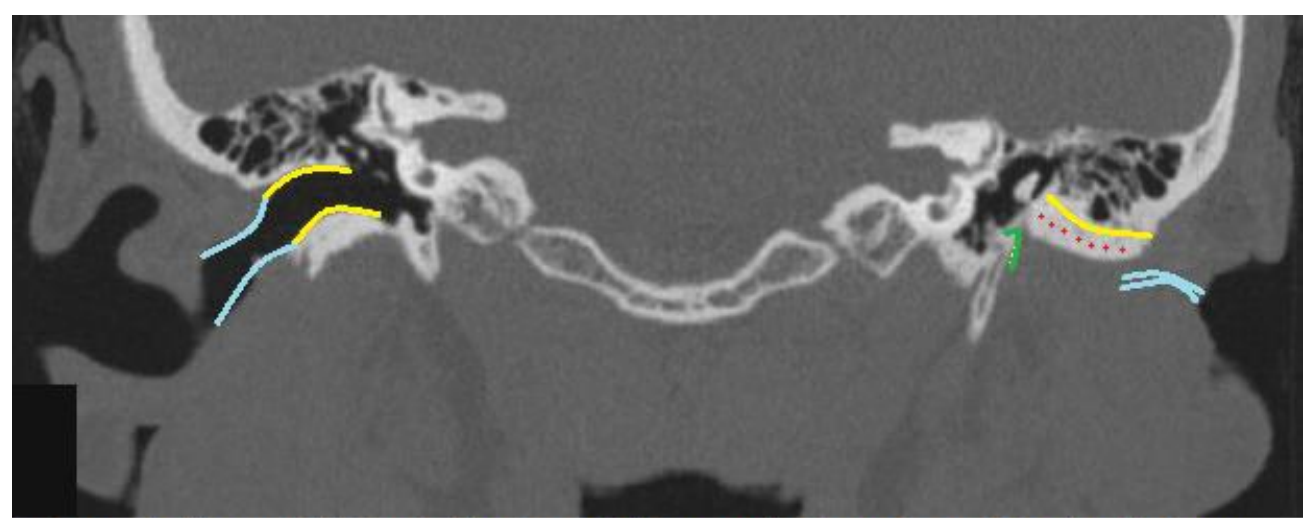

Figure 4: Coronal C.T. cut showing right normal external canal having its bony part marked by the yellow lines and cartilagenous part marked by the blue lines. the left atretic ear showes only the superior bony wall marked by the yellow line with the atretic plate under it marked by red dots and rudimentary inferior bony wall due to hypoplastic tympanic ring marked by the green line. Also in the left side we notice the aproximate site of the malformed cartilage marked by the blue line. 

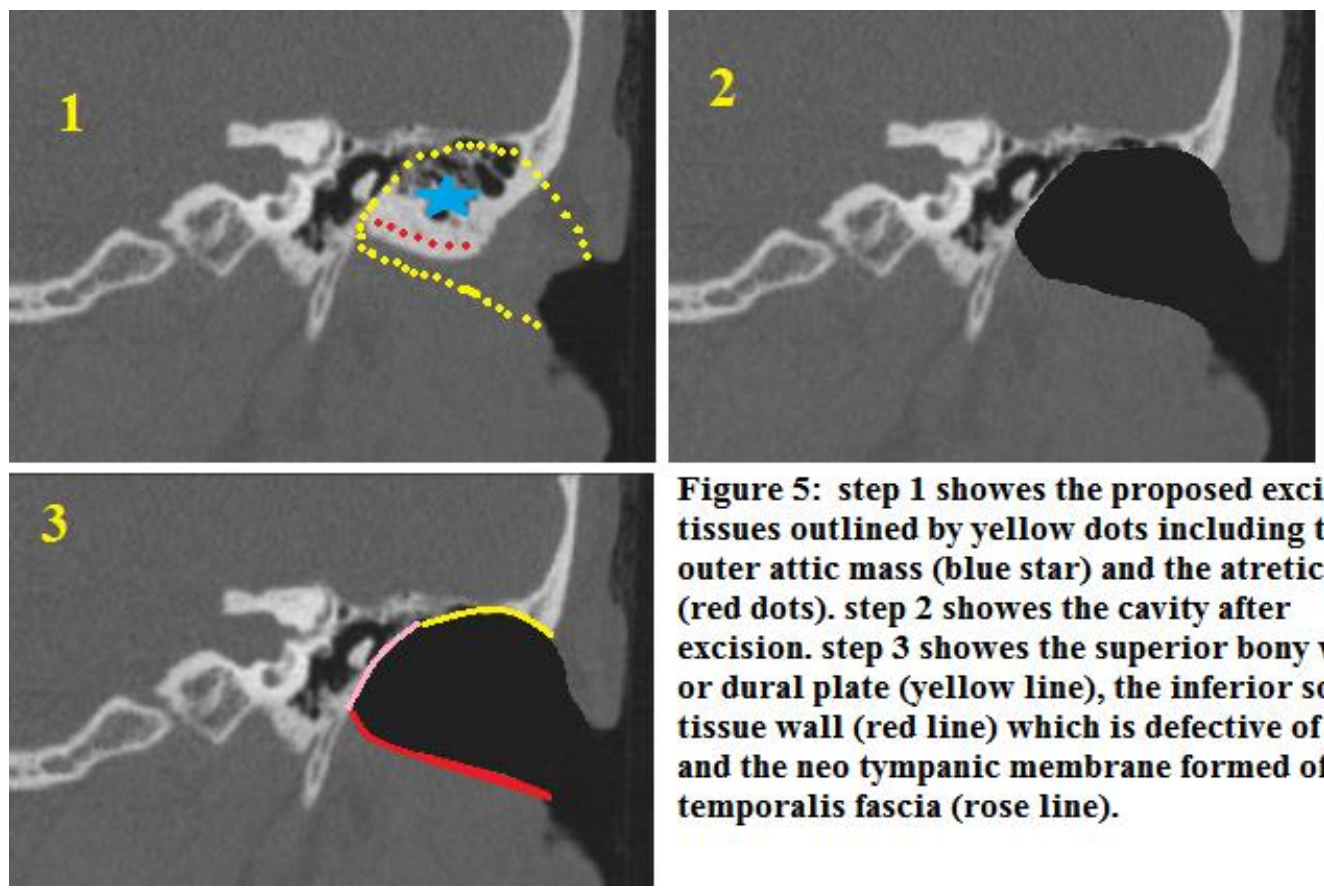

Figure 5: step 1 showes the proposed excised tissues outlined by yellow dots including the outer attic mass (blue star) and the atretic plate (red dots). step 2 showes the cavity after excision. step 3 showes the superior bony wall or dural plate (yellow line), the inferior soft tissue wall (red line) which is defective of bone and the neo tympanic membrane formed of temporalis fascia (rose line).

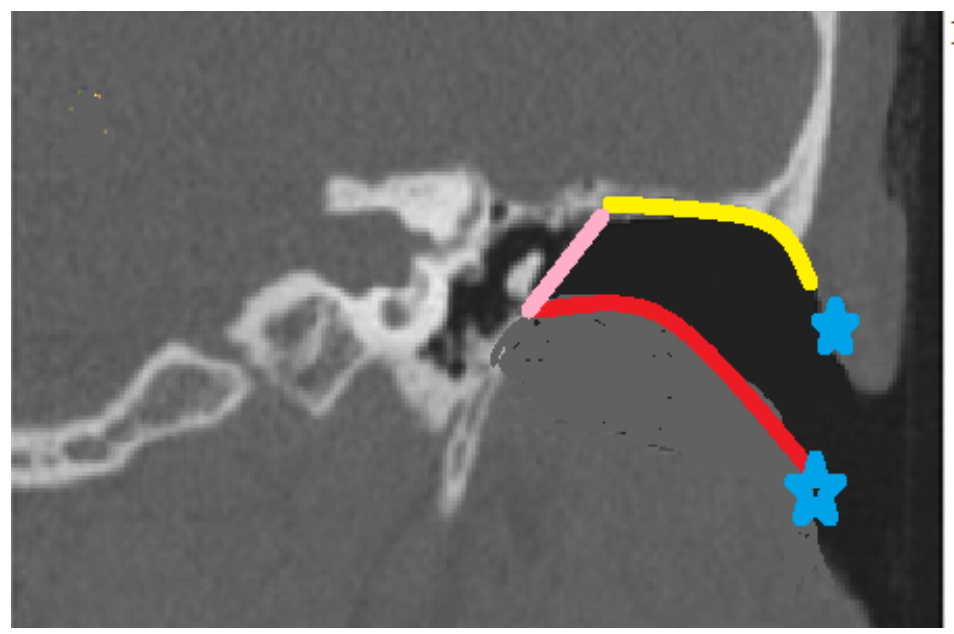

Figure 6 : the cavity in figure 5 was showen here inprogressive narrowing by the inferior soft tissue wall (red line) and progressive narrowing of the meatus because it is devoid of solid skeleton (bone or cartilage)

Blue stars 
Figure 7

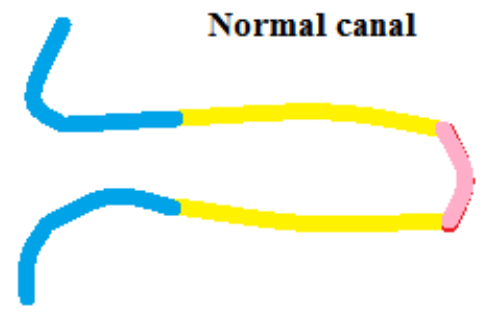

\section{Normal canal depth Inner bony two thirds Outer carilagenous one third continous with the auricular cartilage Normal caliber of the canal}

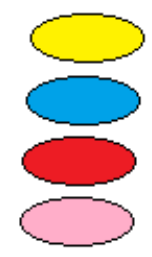

Bone

Cartilage

Soft tissue

Drum

\section{DISCUSSION}

Surgical repair of congenital aural atresia remains a challenging task in our practice. Atresia surgery has multiple risks and unpredictable postoperative scenarios regarding hearing and healing. Risks include injury to the facial nerve, sensorineural hearing loss, failure to close the air-bone gap, and meatal or canal stenosis (14). The goals of atresia repair are to obtain the best possible hearing outcome and to construct a clean, wide, well epithelialized external ear canal which may adapt a hearing aid mold (15).

Surgical candidacy and patient selection depends on several factors and parameters which have been formulated by many authors to construct scoring systems. Jahrsdoerfer scoring system was considered the most popular and useful one. Based on the evaluation of certain anatomical structures on highresolution C.T. scans, the Jahrsdoerfer grading system was developed to determine surgical candidacy and to predict which patients would have more favorable hearing outcomes. Previous studies demonstrated that patients scoring 6 or lower have a worse postoperative hearing outcome (16).

\section{Repaired atresia}

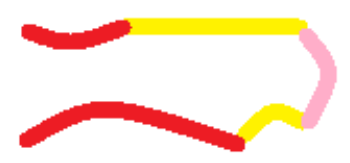

\begin{abstract}
Short superior and
posterior bony wall

Very short inferior wall

No cartilagenous segment

of the canal and replaced

by soft tissue.
\end{abstract}

In a study, lack of middle ear aeration was the only variable that was significantly more correlated with a poorer hearing outcome. This study found no statistically significant difference was noted in the presence or absence of the other 8 anatomical structures of Jahrsdoerfer scale. Lack of aeration may result in difficulty identifying a middle space and ossicular chain during drilling, refixation of the ossicular chain postoperatively, and postoperative stenosis with a constricted middle ear space and smaller tympanic membrane. So, simplification of the Jahrsdoerfer grading scale, or a modified Jahrsdoerfer grading scale was done to determine a patient's candidacy for surgery stressing on 4 primary structures that would immediately preclude surgery. These structures are the position of the tegmen, the location and position of the facial nerve, the presence of middle ear aeration, and the appearance of the stapes bone or oval window (17).

In contrast, other studies have attempted to correlate the surgical anatomy and audiometric outcome with other preoperative factors such as age, severity of microtia, and revision vs. primary surgery. They found that the surgical outcome does not correlate with the 
middle ear aeration only or other middle ear structures which were mentioned in Jahrsdoerfer or modified Jahrsdoerfer grading scale. Similarly, in my study I have noticed that the outcome could not be predicted precisely by the Jahrsdoerfer scoring system in which there was recurrences of stenosis and hearing loss with the highest scores and well developed middle ear and ossicles. I have analyzed the preoperative C.T. scan data and matching it with the intraoperative findings (18). Then I have followed those patients closely through their postoperative months to pick up the gradual and progressive changes. To construct the atretic canal properly we have to get a scoring scale for the canal itself, not the middle ear only. Other previous scales have focused on the middle ear space and its contents and the shape or the development of the auricle bypassing the canal development and its dimensions (19). Reconstruction of the canal is not just burrowing through the obstructing tissues but it should be in the form of building the canal to mimic its components as possible. The external canal is a hollow patent structure with bony and cartilaginous solid walls (figure 7). It has a length and a caliber, so if we are able to mimic these dimensions and construct a conduit from the exterior to the middle ear, the outcome may be favorable. Unfortunately, some dimensions and components of the canal may be uncorrectable. The superior and posterior bony walls are the only bouderies which may be available. The superior wall is composed of the squamous portion of the temporal bone which can be widened in the superior direction by drilling out the outer attic mass to perform Atticotomy up to the level of middle fossa dura. The posteriuor bony wall is formed of the underdeveloped mastoid portion of the temporal bone. It can be widened posteriorly by performing mastoidectomy to the sinus plate especially in patients with narrow atretic plate (20). The anterior and inferior bony walls are remnants due to the rudimentary tympanic ring and temperomandibular joint. The outer cartilaginous third of the canal is absent or replaced by a deformed or stenosed cartilaginous remnants. So, finally the canal will be short or shallow down to its half and the existing canal has only superior and posterior bony walls with opposing inferior and anterior soft tissue walls leading to ultimate collapse and stenosis (figures 5,6). The length or depth of the canal is uncorrectable dimension due to the fact of underdevelopment or no development of this side of the face including the external auditory canal, temperomandibular joint and surrounding soft tissue. So the depth is reduced all over the side of affection whether it is bilateral or unilateral and the middle ear is near to the surface than normal. Also the anterior and inferior bony walls are uncorrectable due to their marked underdevelopment and small size relative to the superior and posterior walls. Additionally we have another uncorrectable dimension which is the vertical or supero-inferior dimension between the tegmen and the tympanic floor. This dimension is limited superiorly by the dura and inferiorly by the small sized thin tympanic ring which should not be drilled completely to obtain inferior bony wall rather than a soft one and to avoid trauma to the anomalous facial nerve. Dimension consideration is of paramount importance either in patients with complete atresia or in patients with partial atresia or stenosis. These uncorrectable dimensions are nearly constant in all cases even those with the highest Jahrsdoerfer scores. The scope of patient selection and surgical candidacy will be narrowed and limited to any patient with suitable dimensions.

\section{CONCLUSION}

Analysis of C.T. data and the intraoperative findings of canal atresia surgery proved the presence of uncorrectable dimensions even with the highest Jahrsdoerfer scores due to lack of full dimension consideration.

\section{REFERENCES}

1 - Anthwal N, Thompson H. The development of the mammalian outer and middle ear. J Anat. $2016 \mathrm{Feb} ; 228(2): 217-32$.

2 - Hall JW. Development of the ear and hearing. J Perinatol. 2000 Dec;20(8 Pt 2):S12-20. 
3 - Urness LD, Paxton CN, Wang X, Schoenwolf GC, Mansour SL. FGF signaling regulates otic placode induction and refinement by controlling both ectodermal target genes and hindbrain Wnt8a. Dev Biol. 2010 Apr 15;340(2):595-604.

4 - Ohyama T, Mohamed OA, Taketo MM, Dufort $\mathrm{D}$, Groves AK. Wnt signals mediate a fate decision between otic placode and epidermis. Development. 2006 Mar;133(5):86575.

5 - Ikui A, Sando I, Haginomori S, Sudo M. Postnatal development of the tympanic cavity: a computer-aided reconstruction and measurement study. Acta Otolaryngol. 2000 Mar;120(3):3759.

6 - Jahrsdoerfer RA, Yeakley JW, Aguilar EA, Cole RR, Gray LC. Grading system for the selection of patients with congenital aural atresia. Am J Otol. 1992 Jan;13(1):6-12.

7 - Shonka DC Jr, Livingston WJ 3rd, Kesser BW. The Jahrsdoerfer grading scale in surgery to repair congenital aural atresia. Arch Otolaryngol Head Neck Surg. 2008 Aug;134(8):873-7.

8 - Tos M. Anatomy and histology of the middle ear. Clin Rev Allergy. 1984 Nov;2(4):267-84.

9 - Takegoshi H, Kaga K. Difference in facial canal anatomy in terms of severity of microtia and deformity of middle ear in patients with microtia. Laryngoscope. 2003 Apr;113(4):635-9.

10 - Dedhia K, Yellon RF, Branstetter BF, Egloff AM. Anatomic variants on computed tomography in congenital aural atresia. Otolaryngol Head Neck Surg. 2012 Aug;147(2):323-8.

11 - Osborn AJ, Oghalai JS, Vrabec JT. Middle ear volume as an adjunct measure in congenital aural atresia. Int $\mathbf{J}$ Pediatr Otorhinolaryngol. $2011 \mathrm{Jul} ; 75(7): 910-4$.

12 - Kelley PE, Scholes MA. Microtia and congenital aural atresia. Otolaryngol Clin North Am. 2007 Feb;40(1):61-80.

13 - Schuknecht HF. Congenital aural atresia. Laryngoscope. 1989 Sep; 99(9):908-17.

14 - Oliver ER, Lambert PR, Rumboldt Z, Lee FS, Agarwal A. Middle ear dimensions in congenital aural atresia and hearing outcomes after atresiaplasty. Otol Neurotol. 2010 Aug;31(6):946-53.

15 - Kountakis SE, Helidonis E, Jahrsdoerfer RA. Microtia grade as an indicator of middle ear development in aural atresia. Arch Otolaryngol Head Neck Surg. 1995 Aug;121(8):885-6.

16 - Mukherji SK, Fatterpekar G, Castillo M, Stone JA, Chung CJ. Imaging of congenital anomalies of the branchial apparatus. Neuroimaging Clin $\mathrm{N}$ Am. 2000 Feb;10(1):75-93.

17 - Benton C, Bellet PS. Imaging of congenital anomalies of the temporal bone. Neuroimaging Clin N Am. 2000 Feb;10(1):35-53.

18 - Fu Y, Zhang T. Facial nerve lying lateral to ossicles in one case of congenital aural atresia. Int J Pediatr Otorhinolaryngol. 2011 Apr; 75(4):597-9.

19 - Jahrsdoerfer RA, Garcia ET, Yeakley JW, Jacobson JT. Surface contour three-dimensional imaging in congenital aural atresia. Arch Otolaryngol Head Neck Surg. 1993 Jan;119(1):95-9.

20 - Swartz JD, Faerber EN. Congenital malformations of the external and middle ear: high-resolution CT findings of surgical import. AJR Am J Roentgenol. 1985 Mar;144(3):501-6.

To Cite

Alzamil, W. Anatomical Barriers in Congenital Canal Atresia Affecting Operative Candidacy and Patient Selection. Zagazig University Medical Journal, 2022; (80-91): -. doi: 10.21608/zumj.2021.90739.2318 